\title{
KEANEKARAGAMAN JENIS VEGETASI MANGROVE DI DESA DUSUN BESAR KECAMATAN PULAU MAYA KABUPATEN KAYONG UTARA
}

\author{
(Species Diversity of Mangrove Vegetation in Dusun Besar Village Pulau Maya District, \\ Kayong Utara Regency)
}

\author{
Cici Khairunnisa, Eddy Thamrin, Hari Prayogo \\ Fakultas Kehutanan Universitas Tanjungpura. J1. Daya Nasional Pontianak 78124 \\ Email : cicikhairunnisa88@gmail.com
}

\begin{abstract}
The diversity of mangrove vegetation is a community that has different characteristics from other communities. Diversity is an important component in mangrove management, but so far the availability of data related to mangroves is still very minimal, including those related to the species diversity of mangrove forest vegetation in the region. This study aims to obtain data on species diversity of vegetation found in the mangrove forest area of Dusun Besar Village, Pulau Maya District, Kayong Utara Regency. Method used was a combination of path and plot method, and the determination of the location and research path location were carried out using purposive sampling. The results of observation and data analysis showed that the dominant vegetation species with the highest importance value index (INP) for seedlings, saplings and trees was the Avicennia marina, namely the INP value of seedlings $37.04 \%$, the INP values of sapling $65.24 \%$, and the value of INP a tree rate of 65. Based on the results of the most dominant analysis found the species of Avicennia marina with a value of $C=0.03430$ for seedling, $C=0.04729$ for sapling, and $C=0.04736$ for tree level. The diversity of mangrove forest vegetation species in Dusun Besar Village for seedlings, saplings and trees is low because it has an $H$ 'value $<1$, and the abundance of mangrove vegetation species was not evenly distributed in each forest area because it only has an e value $<1$.
\end{abstract}

Keywords: Dusun Besar Village, Mangrove Forest, Species Diversity

\section{PENDAHULUAN}

Hutan mangrove merupakan tipe hutan yang tumbuh di daerah pasang surut (terutama di pantai yang terlindung, laguna, dan muara sungai) yang komunitas vegetasinya bertoleransi terhadap kadar garam yang tinggi. Ekosistem hutan mangrove adalah suatu sistem yang terdiri atas organisme (vegetasi, satwa, dan mikroorganisme) yang berinteraksi dengan sistem lingkungannya pada suatu habitat hutan mangrove. Ekosistem mangrove dapat dipandang sebagai habitat bagi vegetasi mangrove dan satwa yang ada di dalamnya. Ekosistem mangrove sangat kompleks, karena terdapat banyak faktor yang saling mempengaruhi, baik di dalam maupun di luar pertumbuhan dan perkembangannya (Lose et al., 2015).

Hutan mangrove di dunia mencapai luas sekitar 16.530.000 ha yang tersebar di Asia 7.441.000 ha, Afrika 3.258.000 ha dan Amerika 5.831.000 ha, sedangkan di Indonesia dilaporkan seluas 3.735.250 ha dan merupakan salah satu negara yang memiliki hutan mangrove terluas di dunia. Luas hutan mangrove Indonesia hampir 50\% dari luas mangrove Asia dan hampir $25 \%$ dari luas hutan mangrove 
dunia (Onrizal, 2010). Provinsi Kalimantan Barat memiliki garis pantai sepanjang $1.163,3 \quad \mathrm{Km}$ yang membentang dari arah utara ke selatan. Sepanjang wilayah pesisir ini terdapat ekosistem mangrove yang dikenal oleh masyarakat sebagai hutan bakau dengan luas sekitar 40.000 ha (Muharamsyah et al., 2019).

Indonesia memiliki tingkat keanekaragaman mangrove tertinggi di dunia, dengan jumlah 202 jenis mangrove yang meliputi 89 jenis pohon, 5 jenis palma, 19 jenis pemanjat, 44 jenis herba tanah, 44 jenis epifit dan 1 jenis paku. Sejumlah 202 jenis tersebut, 43 jenis (diantaranya 33 jenis pohon dan beberapa jenis perdu) ditemukan sebagai mangrove sejati (true mangrove), sementara jenis lain ditemukan disekitar mangrove dan dikenal sebagai jenis mangrove ikutan (asociate asociate) (Noor et al., 2006).

Desa Dusun Besar merupakan salah satu desa di Kecamatan Pulau Maya Kabupaten Kayong Utara yang masih memiliki kawasan hutan mangrove dengan luas 210,08 ha. Masyarakat Desa Dusun Besar memanfaatkan hutan mangrove untuk kehidupan sehari-hari untuk kayu cerocok, tenda pernikahan, tiang pondok sawah atau ladang, sesekali memanfaatkan vegetasi mangrove sebagai kayu bakar dalam waktu tertentu, dan masyarakat juga lebih banyak memanfaatkan daun nipah sebagai atap rumah, atap pondok di sawah atau ladang, dan atap sampan atau katoi. Ketersediaan data yang terkait dengan mangrove belum ada, meskipun memiliki hutan mangrove yang cukup luas termasuk yang terkait dengan keanekaragaman jenis vegetasi hutan mangrove di wilayah tersebut. Data tersebut sangat diperlukan dalam rangka penyusunan rencana pengelolaan maupun pemanfaatan hutan mangrove, sehingga fungsi dan manfaatnya dapat dinikmati secara berkelanjutan. Hal inilah yang mendorong dilakukannya penelitian tentang keanekaragaman jenis vegetasi mangrove di Desa Dusun Besar Kecamatan Pulau Maya Kabupaten Kayong Utara.

Tujuan penelitian ini yaitu untuk mendapatkan data keanekaragaman jenis vegetasi yang terdapat pada kawasan hutan mangrove Desa Dusun Besar Kecamatan Pulau Maya Kabupaten Kayong Utara. Penelitian ini diharapkan dapat memberikan informasi tentang keanekaragaman jenis vegetasi yang terdapat pada kawasan tersebut, dapat berguna bagi masyarakat dan atau sebagai sumber data pemerintah setempat dalam melakukan suatu kegiatan rehabilitasi dan menentukan strategi konservasi untuk kawasan tersebut kedepannya, serta sebagai acuan penelitian lebih lanjut mengenai vegetasi mangrove.

\section{METODE PENELITIAN}

\section{Pelaksanaan Penelitian}

Penelitian dilakukan di Desa Dusun Besar Kecamatan Pulau Maya Kabupaten Kayong Utara dari 1 Juli - 23 Juli 2019. Bahan yang digunakan dalam penelitian ini ialah vegetasi mangrove Desa Dusun Besar, sedangkan alat yang digunakan pada penelitian ini sebagai 
berikut: peta lokasi, GPS (Global Positioning System), tali raffia, pita ukur, parang, kamera, kalkulator, buku panduan pengenalan mangrove di Indonesia, dan tally-sheet. Metode yang digunakan dalam penelitian ini adalah metode survey, dan penentuan lokasi penelitian ditentukan secara purposive sampling dan seterusnya dilakukan dengan metode kombinasi antara metode jalur dan metode garis berpetak. Jalur yang dibuat pada hutan mangrove sekunder dengan jumlah plot yang dibuat sejumlah 65 petak, selanjutnya dilakukan pembuatan petak ukur dengan ukuran 2 x 2 m untuk semai (anakan dengan tinggi kurang dari 1,5 cm), 5 x 5 $\mathrm{m}$ untuk tingkat pancang (diameter pohon lebih kecil dari $10 \mathrm{~cm}$ dan tinggi lebih dari $1,5 \mathrm{~cm}$ ), dan untuk tingkat pohon dengan ukuran 10 x $10 \mathrm{~m}$ (diameter pohon lebih besar atau sama dengan $10 \mathrm{~cm}$ ).

\section{Analisis Data}

Hasil analisis vegetasi dihitung untuk mengetahui indeks nilai penting (INP), indeks dominansi (C) Simpson, indeks keanekaragaman (H') Shannonwiener, dan indeks kelimpahan jenis (e) (Odum, 1993). Indeks nilai penting (importance value index) adalah parameter kuantitatif yang dipakai untuk menyatakan tingkat penguasaan suatu jenis terhadap jenis-jenis lain dalam suatu komunitas (Yuningsih et al., 2013). INP juga dapat digunakan untuk memberikan gambaran tentang peranan suatu jenis mangrove dalam ekosistem.

Kisaran indeks dominansi Simpson adalah $0<\mathrm{C} \leq 0,5$ berarti dominansi rendah (tidak terdapat jenis yang secara ekstrim mendominasi jenis lainnya), kondisi lingkungan stabil, dan tidak terjadi tekanan ekologi terhadap biota di lokasi tersebut. Indeks dominansi $0,5<\mathrm{C}$ $\leq 0,75$ berarti dominansi sedang dan kondisi lingkungan cukup stabil. Indeks dominansi $0,75<\mathrm{C} \leq 1,0$ berarti dominansi tinggi (terdapat jenis yang mendominasi jenis lainnya), kondisi lingkungan tidak stabil, dan terdapat suatu tekanan ekologi).

Odum (1993) mendefinisikan besarnya indeks keanekaragaman jenis yaitu apabila nilai $\mathrm{H}^{\prime}>3$ maka keanekaragaman jenis adalah tinggi atau melimpah, apabila nilai $\mathrm{H}^{\prime} 1 \leq \mathrm{H}^{\prime} \leq 3$ maka keanekaragaman jenis adalah sedang, dan apabila nilai $\mathrm{H}^{\prime}<1$ maka keanekaragaman jenis adalah sedikit atau rendah. Vegetasi mangrove dengan kelimpahan jenis (e) $<1$ memiliki arti kelimpahan jenis mangrove di Desa Dusun Besar tidak merata. Hal ini dapat dikatakan bahwa dalam setiap petak yang diteliti tidak setiap petak selalu memiliki jenis yang sama, dan juga pada setiap jalur tidak semua jalur memiliki jenis yang sama.

\section{HASIL DAN PEMBAHASAN}

\section{Jenis Vegetasi Mangrove di Desa Dusun} Besar

Berdasarkan hasil identifikasi yang telah dilakukan pada seluruh petak pengamatan dengan 65 petak dari 3 titik pengamatan, ditemukan 14 jenis pohon mangrove yang termasuk kedalam 12 famili (Tabel 1), vegetasi mangrove yang ditemukan tersebut 10 jenis diantaranya merupakan kategori mangrove sejati dan 4 jenis mangrove ikutan. 
Tabel 1. Jenis Mangrove yang Ditemukan di Desa Dusun Besar Kecamatan Pulau Maya (Species of Mangrove that Found in Dusun Besar Village Pulau Maya District)

\begin{tabular}{llll}
\hline No & Jenis & Family & Kategori \\
\hline 1 & Acanthus ilicifolius & Achantacea & magrove sejati \\
2 & Acrostichum aureum & Pteridaceae & magrove sejati \\
3 & Aegiceras floridum & Myrsinceae & magrove sejati \\
4 & Avicennia alba & Avicenniaceae & magrove sejati \\
5 & Avicennia marina & Avicenniaceae & magrove sejati \\
6 & Bruguiera parviflora & Rhizophoraceae & magrove sejati \\
7 & Cerbera manghas & Apocynaceae & magrove ikutan \\
8 & Derris trifoliate & Leguminosae & magrove ikutan \\
9 & Excoecaria agallocha & Euphorbiaceae & magrove sejati \\
10 & Melastoma candidum & Melastomaceae & magrove ikutan \\
11 & Nypa fruticans & Arecaceae & magrove sejati \\
12 & Rhizophora apiculata & Rhizophoraceae & magrove sejati \\
13 & Sonneratia alba & Sonneratiaceae & magrove sejati \\
14 & Wedelia biflora & Asteraceae & magrove ikutan \\
\hline Suber & Hasil analisiata
\end{tabular}

Sumber: Hasil analisis data lapangan, 2019

Berdasarkan data yang tertuang pada Tabel 1, ditemukan famili yang memiliki 2 jenis antara lain famili Avicenniaceae dan Rhizophoraceae. Hal ini disebabkan famili tersebut dapat tumbuh dengan baik di tempat yang selalu dilalui pasang surut air laut, tanah berlumpur, dapat mentolerir salinitas air yang tinggi dan hempasan gelombang, selain itu famili Rhizophoraceae juga memiliki kecepatan tumbuh sangat tinggi dan daya adaptasinya sangat baik, serta jenis ini mempunyai sifat vivipar (biji sudah berkecambah pada buah yang masih menempel pada ranting). Penyebab lain ialah karena masyarakat Desa Dusun Besar sedikit yang memanfaatkan jenis vegetasi tersebut.

Sejalan dengan pendapat Mernisa dan Oktamarsetyani (2017) menyatakan sifat vivipar ini menyebabkan banyaknya semai yang tumbuh karena setiap biji yang jatuh ke tanah telah siap berkecambah. Faktor tanah yang berlumpur di hutan mangrove juga sangat mendukung pertumbuhan semai jenis-jenis tersebut, selain itu habitat yang baik bagi semai famili Rhizophoraceae adalah tanah berlumpur dengan pasang surut yang tidak menutupi tunas anakan.

Famili yang lainnya hanya ditemukan 1 jenis saja, hal ini dikarenakan famili yang lain tidak dapat hidup dengan baik ditempat yang sering dilalui pasang surut sehingga menghambat proses pertumbuhan dan ada beberapa jenis yang dimanfaatkan masyarakat sekitar kawasan hutan mangrove, untuk jenis Bruguiera parviflora, Excoecaria agallocha, Nypa fruticans, dan Rhizophora apiculata lebih sering dimanfaatkan pohonnya, jenis Avicennia alba, Cerbera manghas, dan Sonneratia alba hidup dengan baik di pekarangan rumah warga dan pesisir sungai. 
Tabel 2. Jumlah Jenis Mangrove yang Ditemukan di Desa Dusun Besar berdasarkan Tingkat Pertumbuhan (Number of Mangrove Species that Found in Dusun Besar Village based on Growth Level)

\begin{tabular}{|c|c|c|c|c|c|c|}
\hline \multirow[t]{2}{*}{ No } & \multirow[t]{2}{*}{ Nama Ilmiah } & \multirow[t]{2}{*}{ Nama Lokal } & \multicolumn{3}{|c|}{ Jumlah Individu/Ha } & \multirow[t]{2}{*}{ Jumlah } \\
\hline & & & Semai & Pancang & Pohon & \\
\hline 1 & Acanthus ilicifolius & Jeruju & 10 & - & - & 10 \\
\hline 2 & Acrostichum aureum & Piai & 105 & - & - & 105 \\
\hline 3 & Aegiceras floridum & Bakau teruntun & 1 & 5 & 15 & 21 \\
\hline 4 & Avicennia alba & Api-api hitam & 2 & 1 & 16 & 19 \\
\hline 5 & Avicennia marina & Api-api putih & 107 & 78 & 112 & 297 \\
\hline 6 & Bruguiera parviflora & Lenggadai & 34 & 32 & 27 & 93 \\
\hline 7 & Cerbera manghas & Entibar & 14 & 12 & 23 & 49 \\
\hline 8 & Derris trifoliate & Ketuer & 58 & - & - & 58 \\
\hline 9 & Excoecaria agallocha & Buta-buta & 16 & 52 & 49 & 117 \\
\hline 10 & Melastoma candidum & Cengkodok & 4 & - & - & 4 \\
\hline 11 & Nypa fruticans & Nipah & 64 & - & - & 64 \\
\hline 12 & Rhizophora apiculata & Bakau & 44 & 57 & 60 & 161 \\
\hline 13 & Sonneratia alba & Kedabu & 4 & 17 & 29 & 50 \\
\hline 14 & Wedelia biflora & Serunai & 76 & - & - & 76 \\
\hline & Total Jumlah & & 539 & 254 & 331 & 1.124 \\
\hline
\end{tabular}

Sumber: Hasil analisis data lapangan, 2019

Tabel 2 menunjukkan adanya perbedaan jumlah jenis dan jumlah individu yang ditemukan dari ketiga tingkat pertumbuhan di lapangan. Jumlah jenis yang ditemukan pada tingkat semai sebanyak 14 jenis, tingkat pancang 8 jenis, dan tingkat pohon 8 jenis. Jumlah individu yang ditemukan di lapangan bervariasi jumlahnya, pada tingkat semai berjumlah 539 individu/ha, pada tingkat pancang berjumlah 254 individu/ha, dan pada tingkat pohon berjumlah 331 individu/ha.

Jumlah individu yang paling banyak ditemukan pada tingkat-tingkat pertumbuhan adalah jenis Avicennia marina dengan tingkat semai sebanyak 107 individu/ha, tingkat pancang sebanyak 78 individu/ha, dan tingkat pohon sebanyak 112 individu/ha. Hal ini dikarenakan jenis A. marina dapat hidup

dengan baik di daerah yang sering dilalui pasang surut dan lebih bisa mentolerir tingginya salinitas air laut serta jenis tersebut tidak banyak dimanfaatkan masyarakat. Sejalan dengan pendapat Mernisa dan Oktamarsetyani (2017) menyatakan A. marina merupakan jenis pionir pada habitat rawa mangrove di lokasi pantai yang terlindung, juga dibagian yang lebih asin disepanjang pinggiran sungai yang dipengaruhi pasang surut serta di sepanjang garis pantai.

Jenis yang paling sedikit ditemukan untuk tingkat semai dan pohon adalah jenis Aegiceras floridum sebanyak 1 individu/ha untuk tingkat semai dan sebanyak 15 individu/ha untuk tingkat pohon. Hal tersebut disebabkan karena tempat tumbuh A. floridum di daerah mangrove tersebut tanahnya kering tidak 
berlumpur dan tergenang apabila air pasang, sedangkan menurut Muzaki et al., (2012) tempat hidup A. floridum umumnya tumbuh dengan baik pada tepi pantai berpasir hingga tepi sungai dan di area yang tergenang pasang-surut normal dan tepi saluran air yang tergenang secara musiman. Hal ini yang menyebabkan jenis ini sedikit ditemui di kawasan mangrove tersebut.

Jenis yang paling sedikit ditemukan untuk tingkat pancang adalah jenis Avicennia alba sebanyak 1 individu/ha. Hal ini dikarenakan jenis $A$. alba di Desa Dusun Besar pada umumnya banyak dijumpai di pinggiran sungai depan rumah warga yang sengaja ditanam dengan tujuan agar tanah tidak longsor yang menyebabkan pengecilan jalan dan pelebaran sungai. Menurut Muzaki et al., (2012) A. alba biasanya tumbuh di zona terdepan (zona yang paling dekat dengan laut) atau di sepanjang muara sungai, juga termasuk jenis pionir sama dengan jenis A. marina.

\section{Indeks Nilai Penting (INP)}

Berdasarkan rekapitulasi INP tingkat pertumbuhan mulai dari semai, pancang dan pohon untuk semua titik pada Tabel 3, diketahui nilai INP tertinggi pada semua tingkat pertumbuhan adalah jenis Avicennia marina dengan nilai INP $37,04 \%$ tingkat semai, nilai INP sebesar $65,24 \%$ tingkat pancang, dan nilai INP $65,29 \%$ tingkat pohon. Hal ini dikarenakan pada kawasan mangrove tersebut khususnya pada zonasi famili Avicenniacea dan Rhizophoraceae yang berhadapan langsung dengan laut, selalu dilalui pasang surut air laut dan memiliki tanah berlumpur. Sejalan dengan pendapat Halidah (2016) yang menyatakan semai ditemukan dapat tumbuh dengan baik di tepi pantai berlumpur daerah mangrove hingga di substrat yang berkadar garam sangat tinggi.

Tingginya nilai INP juga berkaitan erat dengan substrat yang sebagian besar tanah berlumpur yaitu area endapan terakumulasi dan sesuai bagi tegakan mangrove seperti $R$. mucronata dan $A$. Marina, selain itu hal ini juga dikarenakan tempat tumbuh $A$. marina berada pada bagian depan pantai yang selalu dilalui pasang surut air laut (Kartika et al., 2018). A. marina juga dapat mentolerir salinitas air yang tinggi dan berkaitan dengan karakteristik lingkungan tempat tumbuh berada pada bagian depan pantai yang selalu dilalui pasang surut air laut sehingga jenis $A$. marina dapat tumbuh dengan baik dan mendominasi, A. marina juga dapat tumbuh dan berkembang dengan baik pada salinitas yang mendekati tawar hingga 90\% (Muzaki et al., 2012).

Nilai INP terendah untuk tingkat pertumbuhan semai dan pancang adalah jenis Aegiceras floridum dengan nilai INP $0,97 \%$ tingkat semai, nilai INP sebesar $15,29 \%$ tingkat pancang. Hal tersebut disebabkan karena habitatnya pada tepi pantai berpasir sedangkan di kawasan mangrove Desa Dusun Besar $A$. floridum hidup di daerah dengan tanah yang sedikit keras tidak berlumpur dan tergenang apabila air pasang. Menurut Muzaki et al., (2012) habaitat $A$. floridum umumnya tumbuh di tepi pantai 
berpasir hingga tepi sungai, tercatat pula tumbuh pada substrat berkarang, di area yang tergenang pasang-surut normal dan tepi saluran air yang tergenang secara musiman, dan tidak terlalu mentoleransi terhadap salinitas yang tinggi, tanah dan cahaya yang beragam.

Tomlinson (1986) dalam Mernisa dan Oktamarsetyani (2017) menegaskan bahwa jenis-jenis yang umum ditemukan di kawasan hutan mangrove pesisir pantai kawasan Indonesia dan Malaysia yang merupakan tempat biogeografi jenis-jenis tertentu seperti Rhizophora, Bruguiera, Sonneratia, Avicennia, Ceriops, Lumnitzera dan jenis yang lainnya. Nilai terendah adalah jenis Avicennia alba dengan nilai INP sebesar
19,42\%, hal ini dikarenakan A. alba di Desa Dusun Besar tersebut umumnya hidup di tepi sungai depan rumah warga yang sengaja ditanam agar tidak terjadi erosi, sedangkan jenis $A$. alba sangat cocok hidup di daerah lumpur berpasir.

Momo dan Rahayu (2018) menyatakan bahwa peran suatu jenis dalam suatu komunitas digambarkan dari besarnya indeks nilai penting suatu jenis. Makin besar indeks nilai penting suatu jenis berarti makin besar pula peranan jenis tersebut dalam komunitas hutan dan sebaliknya makin kecil indeks nilai penting suatu jenis berarti makin kecil pula peran jenis tersebut dalam suatu komunitas terhadap kestabilan ekosistem hutan.

Tabel 3. Rekapitulasi Indeks Nilai Penting (INP) Semai, Pancang, dan Pohon Vegetasi Mangrove di Desa Dusun Besar (Important Value Index Recapitulation of Seedlings, Saplings, and Trees of Mangrove Vegetation in Dusun Besar Village)

\begin{tabular}{lllccc}
\hline \multirow{2}{*}{ No } & \multirow{2}{*}{ Nama Ilmiah } & Nama Lokal & \multicolumn{3}{c}{ Indeks Nilai Penting (INP) } \\
\cline { 3 - 6 } & & & Semai & Pancang & Pohon \\
\cline { 3 - 6 } & & INP\% & INP\% & INP\% \\
\hline 1 & Acanthus ilicifolius & Jeruju & 4,20 & - & - \\
2 & Acrostichum aureum & Piai & 28,86 & - & - \\
3 & Aegiceras floridum & Bakau teruntun & 0,97 & 15,29 & 28,36 \\
4 & Avicennia alba & Api-api hitam & 1,15 & 18,95 & 19,42 \\
5 & Avicennia marina & Api-api putih & 37,04 & 65,24 & 65,29 \\
6 & Bruguiera parviflora & Lenggadai & 14,12 & 39,75 & 30,42 \\
7 & Cerbera manghas & Entibar & 5,72 & 32,38 & 32,46 \\
8 & Derris trifoliate & Ketuer & 22,48 & - & - \\
9 & Excoecaria agallocha & Buta-buta & 10,78 & 52,68 & 42,42 \\
10 & Melastoma candidum & Cengkodok & 2,30 & - & - \\
11 & Nypa fruticans & Nipah & 22,81 & - & - \\
12 & Rhizophora apiculata & Bakau & 18,32 & 45,37 & 53,30 \\
13 & Sonneratia alba & Kedabu & 3,08 & 30,34 & 28,31 \\
14 & Wedelia biflora & Serunai & 28,16 & - & - \\
\hline \multicolumn{3}{c}{ Total Jumlah } & $\mathbf{2 0 0}$ & $\mathbf{3 0 0}$ & $\mathbf{3 0 0}$ \\
\hline \multicolumn{5}{c}{ Sumyyyyy}
\end{tabular}

Sumber: Hasil analisis data lapangan, 2019 


\section{Indeks Dominansi (C)}

Indeks dominansi (C) merupakan parameter yang digunakan dalam suatu komunitas untuk menyatakan tingkat terpusatnya dominansi suatu jenis. Berdasarkan hasil analisis yang tertuang pada Tabel 4, diketahui yang paling dominan dijumpai adalah jenis Avicennia marina dengan nilai $\mathrm{C}=0,03530$ untuk tingkat semai, nilai $\mathrm{C}=0,04729$ untuk tingkat pancang, dengan nilai $\mathrm{C}=0,04736$ untuk tingkat pohon. Hal ini disebabkan jenis A.marina pada kawasan hutan mangrove tersebut tumbuh di zonasi paling depan dan berhadapan langsung dengan laut, hidup pada tanah berlumpur dan jenis ini tidak banyak dimanfaatkan oleh masyarakat sehingga masih banyak dijumpai atau paling dominan.

Hotden et al., (2014) menyatakan bahwa suatu vegetasi akan mendominan apabila jenis vegetasi tersebut mampu berkompetisi dengan baik untuk memperoleh unsur hara dari jenis mangrove yang lainnya, tumbuh pada kondisi lingkungan yang mendukung keberhasilan hidupnya, serta didukung oleh faktor lingkungan seperti substrat, salinitas air dan suhu air dibandingkan jenis mangrove lain.

Tabel 4. Rekapitulasi Indeks Dominansi (C) Semai, Pancang, dan Pohon Vegetasi Mangrove di Desa Dusun Besar (Dominance Index Recapitulation of Seedlings, Saplings, and Trees of Mangrove Vegetation in Dusun Besar Village)

\begin{tabular}{lllccc}
\hline \multirow{2}{*}{ No } & Nama Ilmiah & Nama Lokal & \multicolumn{3}{c}{ Indeks Dominansi (C) } \\
\cline { 3 - 6 } & & & Semai & Pancang & Pohon \\
\hline 1 & Acanthus ilicifolius & Jeruju & 0,00044 & - & - \\
2 & Acrostichum aureum & Piai & 0,02082 & - & - \\
3 & Aegiceras floridum & Bakau teruntun & 0,00002 & 0,00259 & 0,00893 \\
4 & Avicennia alba & Api-api hitam & 0,00003 & 0,00399 & 0,00419 \\
5 & Avicennia marina & Api-api putih & 0,03430 & 0,04729 & 0,04736 \\
6 & Bruguiera parviflora & Lenggadai & 0,00498 & 0,01756 & 0,01029 \\
7 & Cerbera manghas & Entibar & 0,00082 & 0,01165 & 0,01170 \\
8 & Derris trifoliate & Ketuer & 0,01263 & - & - \\
9 & Excoecaria agallocha & Buta-buta & 0,00291 & 0,03083 & 0,01999 \\
10 & Melastoma candidum & Cengkodok & 0,00013 & - & - \\
11 & Nypa fruticans & Nipah & 0,01301 & - & - \\
12 & Rhizophora apiculata & Bakau & 0,00839 & 0,02287 & 0,03157 \\
13 & Sonneratia alba & Kedabu & 0,00024 & 0,01023 & 0,00890 \\
14 & Wedelia biflora & Serunai & 0,01983 & - & - \\
\hline \multicolumn{3}{c}{ Total Jumlah } & $\mathbf{0 , 1 1 8 5 5}$ & $\mathbf{0 , 1 4 7 0 2}$ & $\mathbf{0 , 1 4 2 9 6}$ \\
\hline
\end{tabular}

Sumber: Hasil analisis data lapangan, 2019 
Indeks Keanekaragaman Jenis (H')

Indeks keanekaragaman (Index of diversity), merupakan parameter vegetasi yang sangat berguna untuk membandingkan berbagai komunitas tumbuhan, terutama untuk mempelajari pengaruh gangguan faktor-faktor lingkungan atau abiotik terhadap komunitas. Indeks keanekaragaman jenis digunakan untuk mengetahui keadaan suksesi atau stabilitas komunitas (Rochmady, 2015).

Tabel 5. Rekapitulasi Indeks Keanekaragaman Jenis (H') Semai, Pancang, dan Pohon Vegetasi Mangrove di Desa Dusun Besar (Diversity Index Recapitulation of Seedlings, Saplings, and Trees of Mangrove Vegetation in Dusun Besar Village)

\begin{tabular}{|c|c|c|c|c|c|}
\hline \multirow{2}{*}{ No } & \multirow{2}{*}{ Nama Ilmiah } & \multirow{2}{*}{ Nama Lokal } & \multicolumn{3}{|c|}{ Indeks Keanekaragaman Jenis (H') } \\
\hline & & & Semai & Pancang & Pohon \\
\hline 1 & Acanthus ilicifolius & Jeruju & 0,03 & - & - \\
\hline 2 & Acrostichum aureum & Piai & 0,12 & - & - \\
\hline 3 & Aegiceras floridum & Bakau teruntun & 0,01 & 0,06 & 0,10 \\
\hline 4 & Avicennia alba & Api-api hitam & 0,01 & 0,07 & 0,08 \\
\hline 5 & Avicennia marina & Api-api putih & 0,13 & 0,14 & 0,14 \\
\hline 6 & Bruguiera parviflora & Lenggadai & 0,08 & 0,12 & 0,10 \\
\hline 7 & Cerbera manghas & Entibar & 0,04 & 0,10 & 0,10 \\
\hline 8 & Derris trifoliate & Ketuer & 0,11 & - & - \\
\hline 9 & Excoecaria agallocha & Buta-buta & 0,07 & 0,13 & 0,12 \\
\hline 10 & Melastoma candidum & Cengkodok & 0,02 & - & - \\
\hline 11 & Nypa fruticans & Nipah & 0,11 & - & - \\
\hline 12 & Rhizophora apiculata & Bakau & 0,09 & 0,12 & 0,13 \\
\hline 13 & Sonneratia alba & Kedabu & 0,02 & 0,10 & 0,10 \\
\hline 14 & Wedelia biflora & Serunai & 0,12 & - & - \\
\hline \multicolumn{3}{|c|}{ Total Jumlah } & 0,99 & $\mathbf{0 , 8 6}$ & $\mathbf{0 , 8 7}$ \\
\hline
\end{tabular}

Sumber: Hasil analisis data lapangan, 2019

Keanekaragaman jenis vegetasi hutan mangrove di Desa Dusun Besar untuk tingkat semai, pancang, dan pohon tergolong rendah karena memiliki nilai $\mathrm{H}^{\prime}<1$ yaitu niilai total H' untuk tingkat semai sebesar 0,99 , nilai total $\mathrm{H}^{\prime}$ untuk tingkat pancang sebesar 0,86 , dan nilai total H' untuk tingkat pohon sebesar 0,87 (Tabel 5), hal ini menunjukkan bahwa ekosistem mangrove tersebut memiliki produktifitas yang tidak cukup baik dan kondisi ekosistem tidak cukup seimbang, kondisi perairan tidak stabil, dan besarnya tekanan ekologis, serta terdapat suatu komunitas yang mendominasi.
Sejalan dengan pendapat Suwardi et al., (2013) yang menyatakan bahwa keanekaragaman jenis suatu komunitas akan tinggi jika komunitas itu disusun oleh banyak jenis dan tidak ada jenis yang mendominasi, dan suatu komunitas memiliki nilai keanekaragaman jenis yang rendah jika komunitas itu disusun oleh sedikit jenis dan ada jenis yang dominan.

\section{Indeks Kelimpahan Jenis (e)}

Nilai total indeks kelimpahan jenis pada tingkat semai dengan nilai 0,375 , pada tingkat pancang sebesar 0,415 dan pada tingkat pohon sebesar 0,420 . Jenis 
vegetasi penyusun hutan mangrove yang memiliki nilai indeks kelimpahan jenis (e) $<1$ memiliki arti kelimpahan jenis mangrove masih tidak merata pada setiap areal atau kawasan hutannya, hal ini dikarenakan pada setiap petak dan jalur penelitian tidak selalu memiliki jenis yang sama dan ada jenis yang yang mendominan.

Prastomo et al., (2017) menyatakan vegetasi mangrove memiliki kelimpahan (e kurang dari 1) itu berarti kelimpahan jenis mangrove tidak merata, dengan demikian dapat dikatakan bahwa dalam setiap petak yang diteliti tidak setiap petak selalu memiliki jenis yang sama, dan juga pada setiap jalur tidak semua jalur memiliki jenis yang sama. Nilai indeks kelimpahan jenis berguna sebagai panduan bagi masyarakat untuk kedepannya dalam melakukaan pengayaan jenis vegetasi di kawasan hutan mangrove di Desa Dusun Besar Kecamatan Pulau Maya Kabupaten Kayong Utara.

Tabel 6. Rekapitulasi Indeks Kelimpahan Jenis (e) Semai, Pancang dan Pohon Vegetasi mangrove di Desa Dusun Besar (Abundance Index Recapitulation of Seedlings, Saplings, and Trees of Mangrove Vegetation in Dusun Besar Village)

\begin{tabular}{lllccc}
\hline \multirow{2}{*}{ No } & \multirow{2}{*}{ Nama Ilmiah } & \multirow{2}{*}{ Nama Lokal } & \multicolumn{3}{c}{ Indeks Kelimpahan Jenis (e) } \\
\cline { 4 - 6 } & & Semai & Pancang & Pohon \\
\hline 1 & Acanthus ilicifolius & Jeruju & 0,013 & - & - \\
2 & Acrostichum aureum & Piai & 0,046 & - & - \\
3 & Aegiceras floridum & Bakau teruntun & 0,004 & 0,032 & 0,046 \\
4 & Avicennia alba & Api-api hitam & 0,005 & 0,036 & 0,037 \\
5 & Avicennia marina & Api-api putih & 0,051 & 0,069 & 0,069 \\
6 & Bruguiera parviflora & Lenggadai & 0,031 & 0,056 & 0,048 \\
7 & Cerbera manghas & Entibar & 0,017 & 0,050 & 0,050 \\
8 & Derris trifoliate & Ketuer & 0,040 & - & - \\
9 & Excoecaria agallocha & Buta-buta & 0,026 & 0,064 & 0,058 \\
10 & Melastoma candidum & Cengkodok & 0,008 & - & - \\
11 & Nypa fruticans & Nipah & 0,041 & - & - \\
12 & Rhizophora apiculata & Bakau & 0,036 & 0,059 & 0,064 \\
13 & Sonneratia alba & Kedabu & 0,011 & 0,048 & 0,046 \\
14 & Wedelia biflora & Serunai & 0,045 & - & - \\
\hline \multicolumn{3}{c}{ Total Jumlah } & $\mathbf{0 , 3 7 5}$ & $\mathbf{0 , 4 1 5}$ & $\mathbf{0 , 4 2 0}$ \\
\hline
\end{tabular}

Sumber: Hasil analisis data lapangan, 2019

\section{KESIMPULAN}

Jumlah jenis yang ditemukan di hutan mangrove Desa Dusun Besar adalah 14 jenis, dengan nilai INP tertinggi pada tingkat pertumbuhan adalah jenis Avicennia marina dengan nilai INP semai 37,04\% tingkat semai, $65,24 \%$ tingkat pancang, dan $65,29 \%$ tingkat pohon. Keanekaragaman jenis vegetasi hutan mangrove di Desa Dusun Besar untuk tingkat semai, pancang dan pohon tergolong rendah karena memiliki nilai $\mathrm{H}^{\prime}<1$ yaitu nilai total H' untuk tingkat semai sebesar 0,99 , nilai total H' untuk tingkat pancang sebesar 0,86 , dan nilai total $\mathrm{H}^{\prime}$ untuk tingkat pohon sebesar 0,87 . 


\section{SARAN}

Guna mendapatkan data yang lebih lengkap, sebaiknya dilakukan penelitian pada dua lokasi yang berbeda yaitu hutan mangrove primer dan hutan mangrove sekunder agar ada perbandingan jenis vegetasi antara hutan mangrove primer dan sekunder.

\section{UCAPAN TERIMA KASIH}

Penulisan jurnal ini, penulis banyak mendapat bantuan serta masukan dari berbagai pihak, oleh karena itu dalam kesempatan ini penulis mengucapkan terimakasih yang sebesar-besarnya kepada; orang tua saya, Kepala Desa Dusun Besar yang telah memberi ijin penelitian, rekanrekan yang telah membantu selama pelaksanaan penelitian di lapangan, dan Comdev \& Outreaching Universitas Tanjungpura yang telah memberikan bantuan berupa beasiswa selama masa perkuliahaan.

\section{DAFTAR PUSTAKA}

Halidah. 2016. Keanekaragaman Plankton pada Hutan Mangrove di Kepulauan Togean Sulawesi Tengah. Jurnal Inpo Teknis EBONI 13(1):37-44.

Hotden, Khairijon, Isda MN. 2014. Analisis Vegetasi Mangrove di Ekosistem Mangrove Desa Tapian Nauli I Kecamatan Tapian Nauli Kabupaten Napatuli Tengah Provinsi Sumatera Utara. Jurnal FMIPA 1(2):1-11.

Kartika FT, Istomo, Aminah S. 2018. Keanekaragaman Jenis Mangrove di UPT KPHP Bulungan Unit VIII Kalimantan Barat. Jurnal Media Konservasi 23(3):253-261.

Lose MI, Labiro E, Sustri. 2015. Keanekaragaman Jenis Fauna Darat pada Kawasan Wisata Mangrove di
Desa Labuan Kecamatan Lage Kabupaten Poso. Jurnal Warta Rimba 3(2):118-123.

Mernisa M dan Oktamarsetyani W. 2017. Keanekaragaman Jenis Vegetasi mangrove di Desa Sebong Lagoi Kabupaten Bintan. Prosiding Seminar Nasional Pendidikan Biologi dan Biologi. Universitas Negeri Yogyakarta. 39-40b.

Momo H, Rahayu S. 2018. Analisis Vegetasi Hutan di Desa Wambona Kecamatan Wakorumba Selatan Kabupaten Muna Indonesia. Jurnal Akuakultur, Pesisir dan PulauPulau Kecil 2(1):1-16.

Muharamsyah S, Anwari MS, Ardian H. 2019. Keanekaragaman Jenis Mangrove di Desa Mendalok Kecamatan Sungai Kunyit Kabupaten Mempawah. Jurnal hutan Lestari 7(1):189-197.

Muzaki FK, Saptarini D, Kuswytasari ND, Sulistyono A. 2012. Buku Menjelajah Mangrove Surabaya.

Odum, E.P. 1993. Dasar-Dasar Ekologi. Terjemahan oleh Tjahjono Samingan dari Buku Fundamentals of Ecology. Yogyakarta. Gadjah Mada Universitas.

Onrizal. 2010. Perubahan Tutupan Hutan Mangrove di Pantai Timur Sumatera Utara Periode 1977-2006. Jurnal Biologi Indonesia 6 (2): 163-172.

Prastomo RH, Herawatiningsih R, Latifah S. 2017. Keaenekaragaman Vegetasi di Kawasan Hutan Mangrove Desa Nusapati Kabupaten Mempawah. Jurnal Hutan Lestari 5(2):556-562.

Rochmady. 2015. Struktur dan Komposisi Jenis Mangrove Desa Bonea dan Kodiri Kabupaten Muna Sulawesi Tenggara. Prosiding Simposium 
JURNAL HUTAN LESTARI (2020)

Vol. 8 (2) : 325 - 336

Nasional Kelautan dan Perikanan II:85-94.

Suwardi, Tambaru E, Ambeng, Priosambodo. 2013. Keanekaragaman Jenis Mangrove di Pulau Panikiang Kabupaten Barru Sulawesi Selatan. Jurusan Biologi Fakultas Matematika dan Ilmu Pengetahuan Alam Universitas Hasanuddin Makassar.

Yuningsih E, Simbala HEI, Kandou FEF, Saroyo. 2013. Keanekaragaman Vegetasi Mangrove di Pantai Tanamon Sulawesi Utara. Jurnal Biologi fakultas MIPA Universitas Sam Ratulangi Manado. 